\title{
AVANÇOS NA CULTURA DA MACIEIRA NO BRASIL ${ }^{1}$
}

\author{
JOSÉ LUIZ PETRI², GABRIEL BERENHAUSER LEITE ${ }^{3}$, \\ MARCELO COUTO $^{4}$ E POLIANA FRANCESCATTO 5
}

RESUMO - A cultura da macieira no Brasil iniciou seu desenvolvimento comercial na década de 70, sendo que até esta data foram poucos os plantios comerciais, representando menos de 100 ha. Com a iniciativa de alguns produtores pioneiros, incentivos fiscais que permitiam aplicar parte do Imposto de Renda na implantação de pomares e pelo apoio dos governos estaduais com projetos de desenvolvimento, a cultura da macieira teve grande impulso a partir da década de 80. Destaca-se que, na década de 70, o Brasil dependia de importações, representando na época mais de 100 milhões de dólares. Nessa década, produzíamos 13.263 t, passando para 183.299 t e 857.615 t na década de 80 e 90, respectivamente. Atualmente, o Brasil conta com uma área em torno de 37.000 ha, com 3.450 produtores, sendo que, na safra de 2009/2010, foram colhidas 1.253 mil toneladas. Desde 1994, o Brasil passou a exportador de maçãs, sendo que, a partir do ano de 2000,as exportações vêm superando as importações. A cultura da macieira é uma importante fonte de geração de emprego, com três empregos diretos e indiretos por ha, o que representa mais de 100 mil empregos na cadeia produtiva da maçã. Estes avanços devem-se a importantes tecnologias que foram introduzidas ao longo dos anos, que também permitiram um aumento de qualidade e produtividade por unidade de área, onde, na década de 70 e 80 , era inferior a 15t e atualmente está próxima de 40 t/ha, com alguns pomares produzindo acima de $50 \mathrm{t} / \mathrm{ha}$. A evolução ocorreu com as cultivares, com os primeiros plantios realizados com as cultivares Golden Delicious, Starkrimson, Blackjon, entre outras, as quais logo foram substituídas por "Gala" e 'Fuji, e, na década de 90, plantando-se os clones destas cultivares com melhor coloração vermelha dos frutos. Grande evolução ocorreu com a qualidade do material vegetativo em que porta-enxerto e copas estavam infectados com viroses. A introdução de material livre de vírus propiciou aumento na produtividade, permitindo também a utilização de porta-enxertos ananizantes, com plantios em alta densidade. No início dos plantios de macieira, eram plantadas de 500 a 800 plantas por ha, sendo que atualmente são utilizadas 2.500 a 3.000 plantas em média por ha. Como a região produtora de maçã no Sul do Brasil não tem o frio suficiente para atender às necessidades para a saída da dormência, tecnologias foram desenvolvidas para a indução de brotação e floração, permitindo estabilidade na produção. Afora estas tecnologias, devem ser ressaltados os avanços nos sistemas de condução e poda, manejo de colheita, raleio químico, polinização, controle fitossanitário e conservação e armazenagem da fruta, sendo que esta última permitiu o abastecimento do mercado nos 12 meses do ano com fruta de ótima qualidade. A maçã foi pioneira na implantação do sistema de produção integrada, sendo a primeira fruta brasileira a ser certificada neste sistema.

Termos para indexação: Malus domestica, histórico, produção, tecnologias.

\section{ADVANCES OF THE APPLE CROP IN BRAZIL}

\begin{abstract}
The boom of the commercial apple production in Brazil was set by the ' 70 s, since up to this date there were few commercial orchards, representing less than 100ha. By the initiative of some pioneer growers, and the fiscal incentive that allowed investing part of the income tax on orchard implantation and the support of state governments to developing projects, the apple culture had and expressive boost from the ' 80 s. In the ' 70 s, Brazil depended on importations, what represented at that time more than 100million dollars. The production was approximately 13,263ton and reached 183,299ton and 857,615ton in the ' 80 s and ' 90 s, respectively. Recently, Brazil has reached an producing area of around 37,000ha with 3450 growers,
\end{abstract}

\footnotetext{
${ }^{1}$ Palestra Sinfruit 096 - Simpósio Internacional de Fruticultura - Avanços na Fruticultura (17 a 21 Outubro)

${ }^{2}$ Eng. Agr. M.Sc. Pesquisador da Epagri - Estação Experimental de Caçador (EPAGRI) - Caixa Postal 591, Caçador-SC - Cep: 89500000.Email: petri@epagri.sc.gov.br

${ }^{3}$ Eng. Agr. D.S. Pesquisador da Epagri - Estação Experimental de Caçador (EPAGRI) - Caixa Postal 591, Caçado- SC - Cep: 89500000. Email: gabriel@epagri.sc.gov.br

${ }^{4}$ Eng. Agr. D.S. Pesquisador da Epagri - Estação Experimental de Caçador (EPAGRI) - Caixa Postal 591, Caçador-SC - Cep: 89500000. Email: marcelocouto@epagri.sc.gov.br

${ }^{5}$ Eng.Agr. M.Sc. Doutoranda do PPGA/UFSC/EPAGRI - Estação Experimental de Caçador (EPAGRI) - Caixa Postal 591, Caçador-SC - Cep: 89500-000. Email: polianafran@yahoo.com.br
} 
and in 2009/2010 it was harvested 1,253 thousand tons of apples. Since 1994, Brazil became an apple exporter, and after 2000 exportations have beaten importations. The apple sector is an important source of employment generation with three direct and indirect jobs per hectare, representing more than 100 thousand employment in the apple productive chain. These advances are due to important technologies that were introduced throughout the years, which also let an increase of quality and yield per unit of area; in the " $70 \mathrm{~s}$ and ' 80 s yield was inferior to 15 ton/ha and nowadays is near to 40 ton/ha, although some areas produce above 50ton/ha. Evolution also occurred with the cultivars. The first plantings were based on the cultivars Golden Delicious, Starkrimson, Blackjon, etc. These cultivars were progressively being substitute by 'Gala' and 'Fuji', and from the '90s clones that produce redder fruits of both cultivars were planted. Greater progress occurred to the quality of the vegetative material, since rootstocks and scions were virus-contaminated. The introduction of free-virus material led to an increase in yield and to the use of dwarfing rootstocks in high density orchards. The first apple orchards were performed with 500 to 800 trees per hectare; currently, orchard density consists of 2500 to 3000 trees per hectare. As the apple producing region in the South of Brazil has no adequate chilling to attempt the requirements to release dormancy, technologies were developed to induce bud burst and blooming, and consequently no alternate bearing. Besides these technologies, it must be highlighted the advances in the training systems and pruning, harvest management, chemical thinning, pollination, phytosanitary control and fruit conservation and storage. Moreover, the latter permitted the market supplying for twelve months of the year with high quality fruits. Apple was the pioneer fruit in the implantation of the integrated production system and the first Brazilian fruit to be certified in this system.

Index Terms: Malus domestica, historical, production, technologies.

\section{INTRODUÇÃO}

Embora a cultura da macieira em escala comercial tenha iniciado na década de 1970 , são inúmeras as referências sobre a introdução de cultivares, iniciativas de plantio ou fomentos anteriores a esse período. A primeira referência sobre as macieiras no Brasil é de 1903, quando Rossi (SANTOS, 1994) faz menção à macieira cultivar Bismark, que crescia no jardim do Sr. Donner, em uma localidade próxima de Indaial-SC, e também próxima a Brusque-SC.

No ano de 1913, em um diagnóstico do ministério da agricultura sobre as condições de agricultura dos municípios de Santa Catarina, destacava-se que, no município de São Joaquim, foram encontradas árvores frutíferas de pessegueiro, macieira, ameixeira, marmeleiro e figueira, produzindo boas frutas, sendo também citados como locais promissores para a produção de frutas temperadas as regiões de Lages, Curitibanos, São Bento, Campos Novos e Canoinhas (SCHMIDT, 1990).

No Brasil, o primeiro cultivo comercial ocorreu em 1926, provavelmente no município de Valinhos-SP, pelo produtor Batista Bignet, com a cv. Ohio Beauty e, em 1927, José Trombetta, comercializando mudas desta cultivar. Entre 1940 e 1960, havia no município de Valinhos cerca de 500 mil a 1 milhão de plantas de macieira, principalmente da cultivar Ohio Beauty, que era conhecida também como Valinhos. No final da década de 60 , com as orientações do instituto Agronômico de Campinas, o cultivo da macieira expandiu-se enormemente no
Vale de Parapanema em São Paulo (BREICHER, 2002).

No Rio Grande do Sul, em 1948, já existiam pomares com a cv. Valinhense (Ohio Beauty) e outras no município de Caxias do Sul, e logo a seguir no município de Veranópolis, onde foi plantada a cv. José Bin.

No final da década de 1960 , incentivadas por René Frey, as famílias Evrard e Mahler, fruticultores oriundos da Argélia, vieram para Fraiburgo. Em Fraiburgo, fundaram a Sociedade Agrícola Fraiburgo, Ltda. - Safra, tendo como objetivo inicial o desenvolvimento da vitivinicultura; no entanto, outras coleções de diversas fruteiras de clima temperado, entre as quais a macieira, foram instaladas. Diante das dificuldades encontradas, em 1965, a Sociedade Agrícola Fraiburgo trouxe o Sr. George Delbard, um dos maiores viveiristas da Europa, para visitar Fraiburgo e toda a região. Após esta visita, foram importadas cerca de 100.000 mudas, das diversas fruteiras de clima temperado, porém com maior destaque para a macieira.

Diante dos primeiros resultados obtidos, o então Secretário da Agricultura de Santa Catarina, Sr. Luiz Gabriel, apresentou em 1968 um projeto para desenvolver esta atividade no Estado, sendo que, em dezembro do mesmo ano, o governo estadual, através da Lei ${ }^{\circ} 4.263$, criou o Profit - Projeto de Fruticultura de Clima Temperado, sendo implantado na gestão do Eng. Agr. Glauco Olinger, que substituiu Luiz Gabriel na Secretaria da Agricultura.

Em 1969, a firma Reflorestamento Fraiburgo, 
liderada pelo Sr. Willy Frey, implantou o primeiro pomar comercial de macieira, aproveitando a Lei federal $n^{0} 5.106$, conhecida como lei dos incentivos fiscais, que permitia abater 50\% do Imposto de Renda devido no exercício para aplicação em reflorestamento, podendo ser feita com árvores frutíferas. Esta lei deu o grande impulso inicial ao desenvolvimento da cultura da macieira no Brasil. A partir destes plantios, a macieira começou a ser plantada, principalmente, nos Estados de Santa Catarina e Rio Grande do Sul, formando-se três polos de produção: Fraiburgo, São Joaquim e Vacaria.

Em termos de pesquisa com macieira, o passo inicial foi dado em 1928, com a criação da Estação Experimental de São Roque, pertencente ao Instituto Agronômico de Campinas - SP, com a introdução de 72 cultivares de macieira, a maioria de origem Europeia. Entre 1935 e 1944, o produtor Albino Brueckner selecionou uma cultivar que recebeu o nome de Brasil, também conhecida como Brueckner do Brasil, que provavelmente é originária de uma semente da cv. Gravensteiner, sendo muito plantada no Estado de São Paulo. Em 1947, o engenheiro agrônomo Orlando Regitano iniciou um programa de melhoramento de fruteiras de clima temperado no Instituto Agronômico de Campinas, do qual resultou a obtenção da cultivar de macieira Rainha, lançada em 1975 (OJIMA et al., 1993).

Em Santa Catarina, a partir da década de 1970, a Estação Experimental de São Joaquim, vinculada à Secretaria Estadual da Agricultura e liderada pelo pesquisador Pedro Alcântara Ribeiro, impulsionou os trabalhos na cultura da macieira, tendo a colaboração do governo Japonês na pessoa do técnico Kenshi Oshirozawa. Do mesmo modo, a Estação Experimental de Videira, pertencente ao Ministério da Agricultura e liderada pelo pesquisador Mário de Pellegrin, implantou em 1968 uma coleção de cultivares, principalmente com as do grupo Delicious. Este trabalho também se estendeu, a partir de 1970, ao acompanhamento da coleção de macieiras da Empresa Sociedade Agrícola Fraiburgo, onde já constavam as cvs. Gala e Fuji, identificadas como PX 1035 e Tohoku 7, respectivamente. Também neste mesmo período, a antiga Estação Experimental de Cascata, atualmente pertencente o Centro Nacional de Pesquisa de Clima Temperado (CPACT), da Embrapa, em Pelotas, desenvolvia trabalhos com coleções de macieira.

A partir de 1973, o Estado de Santa Catarina, através da Empresa de Pesquisa Agropecuária de Santa Catarina (EMPASC) e da sua sucessora, Empresa de Pesquisa e Extensão Rural de Santa Catarina (Epagri), ampliou as pesquisas com a macieira e estabeleceu um programa de melhoramento genético, lançando inúmeras cultivares, com destaque para a Fuji Suprema, Catarina, Daiane, Monalisa e Condessa. Na década de 1980, também o IAPAR, no Paraná, desenvolveu pesquisas em melhoramento genético, lançando a cultivar Eva, de baixa exigência em frio, hoje plantada em regiões quentes, inclusive na Bahia. A literatura brasileira sobre a cultura da macieira tem como uma das primeiras referências em 1936, quando João Decker publicou um livro sobre os aspectos biológicos da flora brasileira, no qual faz referências botânicas à macieira. Em 1953, José de Almeida Santos Neto, pesquisador do IAC, publica o livro Cultura da Macieira e, em 1957, o engenheiro agrônomo Euclides Palma Guião, do IAC, publicou o boletim Instruções Práticas para a Cultura da Macieira. Nos anos sessenta e setenta, diversos artigos sobre técnicas de produção da macieira foram publicados, principalmente em São Paulo. O primeiro sistema de produção da macieira foi publicado pela Embrapa em 1975. Em 1978, EMPASC publica A Cultura da Macieira, com 295 páginas, de autoria de Kenshi Ushirozawa e, em 1986, é publicado o livro Manual da Cultura da Macieira, com 562 páginas, sendo composto por diversos autores, o qual foi reeditado em 2002. A partir dos anos 80, foram inúmeras as publicações sobre a cultura da macieira, mostrando sua importância na fruticultura brasileira.

\section{O AGRONEGÓCIO DA MAÇÃ}

O agronegócio da maçã localiza-se no Sul do Brasil, envolvendo seus três estados, notadamente nas regiões mais frias dos mesmos, destacando-se a região de Vacaria, no Rio Grande do Sul, São Joaquim e Fraiburgo, no Estado de Santa Catarina, e de Palmas, no Estado do Paraná. Atualmente, a cultura da macieira está expandindo-se para outras regiões, inclusive para regiões não tradicionais ao cultivo de frutas de clima temperado.

Em uma área plantada de 38,2 mil ha, a produção brasileira de maçã foi de 1,2 milhão de toneladas na safra de 2009/2010 (ICEPA, 2010). O crescimento da área plantada e o volume de produção são apresentados nas Figuras 1 e 2. O volume da safra brasileira pode ser considerado expressivo se levarmos em conta que, nos anos 70, a produção nacional praticamente inexistia (KREUZ; BERNARDI, 1986). Observa-se que o Brasil, em 40 anos, passou de país importador à autossuficiência, sendo o ano de 1998 um marco importante, pois o Brasil passa ao status de país exportador (Figura 3). Nesta atividade, estão envolvidos mais de 3 mil produtores, gerando em torno de 150 mil empregos diretos e indiretos. Com o desenvolvimento da cultura da macieira, veio 
a cadeia do frio, sendo que, atualmente, a capacidade estática de armazenagem, em atmosfera convencional e modificada, é de 705 mil toneladas (Figura 4).

\section{TECNOLOGIAS INTRODUZIDAS NO DESENVOLVIMENTO DA CULTURA}

O jornal Good Fruit Grower, de janeiro de 2008, publicou o Ranking dos 28 principais países produtores de maçã, em termos de competitividade internacional, levando em consideração a eficiência produtiva, infraestrutura, recursos financeiros e mercado. Na eficiência produtiva, são levadas em consideração a percentagem de novas cultivares, a densidade de plantio e a produtividade. $\mathrm{Na}$ infraestrutura, consideram-se a capacidade de armazenagem e packing house, a eficiência na distribuição e os sistemas de marketing, entre outros. Nos recursos financeiros e condições de mercado, são levados em conta as taxas de juros, a inflação, a disponibilidade de capital, o controle de qualidade, a exportação, a média do preço de exportação e a média de distância ao mercado. Neste ranking, o Brasil está em $14^{\circ}$ lugar no geral. Quanto à eficiência produtiva e infraestrutura, relacionadas as tecnologias utilizadas, o Brasil está na $7^{a}$ posição, o que demonstra a evolução em termos de inovações tecnológicas introduzidas na cultura da macieira.

\section{Cultivares}

O sucesso com a cultura da macieira no Brasil está ligado aos avanços tecnológicos que acompanharam a cultura. Um dos principais fatores a considerar neste sucesso são as cultivares utilizadas. Nos primeiros plantios, foram utilizadas as cvs. Golden Delicious, Starkimson, Blackjon e Melrose. Entretanto, estas foram rapidamente substituídas por Gala e Fuji, que despontavam em nível internacional como cultivares promissoras. Atualmente, representam 14,89\% e $7,20 \%$ da produção mundial, respectivamente. Estima-se que, em 2020, estarão na terceira colocação em volume mundial de produção. No Brasil, os grupos Gala e Fuji representam em torno de $60 \%$ e $30 \%$ da produção, respectivamente. Já a partir do início da década de 1980, foram introduzidos clones destas cultivares, com melhor coloração, como Royal Gala, Imperial Gala, Maxi Gala, Brookfield, Fuji Suprema, Fuji Seleta e Mishima, que possibilitaram viabilizar a exportação e, assim, atender às exigências do mercado externo. Para as regiões com pouco frio, destaca-se a cv. Eva, que é comercializada nos meses de dezembro e janeiro. Novas cultivares oriundas dos trabalhos de melhoramento genético, como Daiane e Monalisa, vêm sendo introduzidas, porém ainda representam menos de 5\% da área plantada.

\section{Introdução e plantio de material livre de vírus}

No final da década de 1970, foi constatado que as plantas de macieira apresentavam um reduzido crescimento, principalmente a cv. Gala, sendo posteriormente diagnosticado que tanto porta-enxertos quanto o material de copa estavam altamente infectados por viroses. Na cv. Gala, a incidência do vírus lenho-mole (Apple rubbery wood) foi observado em $75 \%$ das plantas, comprometendo o plantio dessa cultivar. Visando a disponibilizar material livre de vírus, foram importados da Estação Experimental de East Malling, na Inglaterra, materiais copa e porta-enxerto das principais cultivares, os quais foram multiplicados e distribuídos pela EMPASC aos viveiristas. Esse material propiciou maior desenvolvimento das plantas e consequente aumento de produtividade de $25 \%$ a $50 \%$. Essa melhoria na condição sanitária do material genético viabilizou a utilização de porta-enxertos ananizantes, o que permitiu, posteriormente, o aumento da densidade de plantio.

\section{Polinização}

Um dos fatores que contribuiu para a baixa produtividade no início dos plantios, foram as falhas nos sistemas de polinização, principalmente com a $\mathrm{Cv}$. Gala. A definição das polinizadoras e o percentual das mesmas nos pomares trouxeram aumento e regularidade na produção. Em pomares já implantados, recomendaram-se técnicas de sobre-enxertia, o uso de "buques" e/ou polinização manual para corrigir o problema. No início da década de 2000, começou-se a utilizar cvs. polinizadoras específicas, conhecidas como Mallus, as quais, além da abundante floração, permitem o seu plantio entre as plantas produtoras, sem perda efetiva no estande de produção.

\section{dormência \\ Desenvolvimento de métodos de quebra de}

As cultivares Gala e Fuji necessitam mais de 600 horas de frio $\left(\leq 7,2^{\circ} \mathrm{C}\right)$ para brotarem e florescerem uniformemente. Quando esta condição não ocorre, a brotação e a floração são desuniformes, com reflexos negativos na produtividade. Nestas condições, o uso de produtos químicos para a indução da brotação e da floração é imprescindível para a viabilidade do cultivo de macieira em regiões de inverno ameno, propiciando regularidade na produção, tornando, deste modo, a produção de maçã no Brasil competitiva. Esta tecnologia já vem sendo utilizada há mais de 25 anos e consiste basicamente na mistura do óleo mineral com Cianamida hidrogenada. O benefício do uso desta tecnologia, além de proporcionar economia ao produtor, trouxe aumento 
de produtividade, visto que, em determinados anos e regiões, a produtividade pode ser drasticamente reduzida se a quebra de dormência das plantas não for feita adequadamente. Novas alternativas de produtos foram desenvolvidas, permitindo dar opções ao produtor. Atualmente, para a recomendação da indução da brotação e floração, a Epagri realiza o monitoramento das unidades de frio em diversas regiões onde se produz frutas de clima temperado, visando a estimar a época de superação da dormência e a data provável de brotação, possibilitando, assim, a recomendação da época de aplicação e concentração dos indutores de brotação. O domínio da tecnologia de indução da brotação e floração da macieira, pela aplicação de indutores de brotação, foi fator decisivo para o sucesso do cultivo da macieira no Sul do Brasil, permitindo o uso de cultivares de média e alta exigências em frio, como Gala e Fuji.

\subsection{Introdução e adaptação de métodos de plantio de macieira em alta densidade}

No início da década de 1970, os primeiros plantios foram conduzidos no sistema de Taça, com densidade de plantio de 550 a 800 plantas ha $^{-1}$. Com o uso de material genético livre de vírus, porta-enxertos ananizantes, interenxertos e sistema de condução em líder central, foi possível mudar para plantios em alta densidade, com espaçamentos de 3,5 a 4,5m x 0,80 a $1,50 \mathrm{~m}$ com um estande de planta de 1.500 a 3.500 plantas $\mathrm{ha}^{-1}$, proporcionando aumento da produção por unidade de área, antecipação na entrada em frutificação, redução da utilização de mão de obra no manejo de pomares e, consequentemente, aumento da rentabilidade do agronegócio da maçã. A utilização destas novas tecnologias de manejo de pomares pode ser considerada um dos maiores avanços na cultura da macieira em relação ao início da mesma no Brasil. $\mathrm{O}$ aumento da densidade de plantio é um dos fatores mais importantes no aumento da produtividade. As Tabelas 1 e 2 evidenciam a influência da densidade de plantio no aumento da produtividade.

\section{Desenvolvimento da tecnologia de raleio químico}

Esta tecnologia gerou grande impacto na fruticultura brasileira, uma vez que o raleio químico reduz consideravelmente a necessidade mão de obra e, consequentemente, o custo de produção. Além do aspecto econômico, pomares tratados com agentes químicos de raleio tendem a produzir frutas de melhor qualidade, com aumento de peso médio dos frutos e com maior regularidade de produção, evitando-se a alternância de produção.

\subsection{Controle de doenças e pragas}

Inúmeros avanços ocorreram no controle de doenças e pragas, sendo que, no início da cultura, eram realizados através de calendários fitossanitários, tendo posteriormente evoluído para sistemas de previsão baseados nas condições climáticas, propiciando a redução do número de tratamentos fitossanitários. Destacam-se os avanços no controle da mancha de Gala (Colletroticun spp) que ameaçava a utilização da cv. Gala no Brasil, sendo o uso desta cultivar viabilizado pelas novas técnicas de controle desenvolvidas pela pesquisa agropecuária brasileira. Com relação à sarna da macieira, a determinação do período de infecção e, consequentemente, o momento da intervenção, aliado à informatização das estações meteorológicas permitiram que informações de controle da doença fossem acessadas diretamente na Internet ou via telefone celular. Com relação a pragas, destaca-se o controle biológico do ácaro (Panonicus ulmi), que em muitos casos eliminou o uso de acaricidas, e o controle de lagartas pelo uso de feromônio. No caso da mosca-das-frutas (Anastrepha fraterculus), avanços ocorreram no monitoramento, determinando-se o número de moscas capturadas por frasco para que ocorra a intervenção química.

\section{Produção Integrada e Certificação}

O programa de produção integrada de Maçã (PIM) foi pioneiro no Brasil. O seu desenvolvimento foi iniciado em 1996 e já na safra de 2002/2003 foi implantado o sistema de certificação, com adesão voluntária junto às entidades certificadoras (FIORAVANÇO, 2009). Atualmente na Região Sul, aproximadamente $60 \%$ da área cultivada com macieira adota este sistema (ANUÁRIO, 2008).

A PIM foi o primeiro sistema a desenvolver as normas e a obter a certificação oficial do Ministério da Agricultura, sendo ampliado para outras culturas. O sistema preconiza a inspeção e a calibração dos pulverizadores, melhorando a eficiência dos tratamentos fitossanitários e possibilitando a rastreabilidade da fruta.

Além destes sistemas, os produtores adotam outros sistemas de certificação, como o Global Gap, entre outros. Isto permite não só a rastreabilidade da fruta, mas também a segurança ao consumidor, pois seguidores destes sistemas somente utilizam produtos registrados para a cultura, produzido frutos com garantia da isenção de resíduos químicos acima dos limites permitidos. A PIM permitiu ao Brasil atingir novo patamar de produção, com foco na melhoria da qualidade, segurança alimentar e preservação do meio ambiente (MELLO, 2004). 
Uso de reguladores de crescimento

O cultivo da macieira em condições de inverno ameno reduz a produtividade e a qualidade dos frutos, sendo o uso de substâncias reguladoras de crescimento importante para a vviabilização da cultura no Brasil. Estas substâncias melhoram a qualidade dos frutos e mantêm a regularidade da produção, promovem o aumento do tamanho e a melhoria na forma dos frutos, incrementam a frutificação efetiva, reduzem a incidência de russeting, melhoram a coloração dos frutos, promovem o controle da queda de frutos na pré-colheita e o controle do crescimento das plantas. Um exemplo do avanço no uso de reguladores de crescimento é o escalonamento da colheita da cv. Gala. O uso de reguladores de crescimento retarda a maturação dos frutos em até 25 dias, o que permite também racionalizar o uso da mão de obra, reduzir o número de repasses na colheita, aumentar o tamanho dos frutos e melhorar a frigoconservação desta cultivar.

O controle do crescimento das plantas traz importantes benefícios aos produtores de maçã, reduzindo mão de obra de poda e melhorando a eficiência dos tratamentos fitossanitários. Neste contexto, aplicações de Proexadione cálcio mostram-se eficientes e em breve estarão incorporadas ao sistema de produção da maçã. Em condições adversas de polinização, o uso de reguladores de crescimento tem amenizado este problema, propiciando aumento de produtividade acima de $50 \%$.

\section{Colheita e conservação da maçã}

Para permitir uma adequada armazenagem, é fundamental estabelecer os índices físico-químicos do ponto de colheita. Esses índices têm sido usados como guias para estimar o estádio de maturação e o ponto de colheita por técnicos. Para complementar, a Epagri desenvolveu um catálogo de cores de fundo da maçã, que tem sido amplamente utilizado no setor produtivo para estimar o ponto ideal de colheita das frutas em nível de pomar.

Após a colheita, as condições de armazenagem da maçã é um dos fatores de maior importância para manter a qualidade da fruta e possibilitar o abastecimento do mercado por longos períodos, sendo que a setor da maçã apresentou grandes avanços ao longo dos anos com investimentos em câmaras frigoríficas e novas tecnologias, como a armazenagem sob atmosfera modificada (AM). A capacidade de armazenagem apresentou um crescimento constante, representando hoje cerca de $70 \%$ da produção, sendo que, desta, mais de 50\% em AM. As máquinas classificadoras são modernas, com sensores de cor, peso e forma totalmente automatizados.

Problemas de armazenagem foram surgindo, como, por exemplo, danos de $\mathrm{CO}_{2}$ na $\mathrm{Cv}$. Fuji quando armazenada em atmosfera modificada, porém estudos foram feitos para determinar o nível ideal de $\mathrm{CO}_{2}$ para a armazenagem da 'Fuji' e para o uso de sistemas de adsorção de $\mathrm{CO}_{2}$ no ambiente de armazenagem. Também a tecnologia do 1-MCP para o aumento da conservação da qualidade pós-colheita foi rapidamente introduzida, o que permitiu ganhos significativos no período de armazenagem, principalmente na cultivar Gala, beneficiando também o consumidor com uma fruta de melhor qualidade. As melhorias na tecnologia de armazenamento de maçãs reduziram as perdas por podridões, como Penicilliun na Cv. Fuji.

Ainda existem demandas para promover avanços no sistema de comercialização, desde o transporte até o ponto final de comercialização.

\subsection{Desenvolvimento de protocolos de} análises químicas dos teores minerais em tecidos foliares e na polpa fresca de maçãs

Devido à complexidade de fatores que agem na nutrição das plantas frutíferas já estabelecidas, a análise de solo isoladamente não fornece indicativos suficientes para se avaliar e quantificar a necessidade de adubação. Porém, a análise de solo deve ser feita para se avaliar a necessidade de reaplicação de corretivos de acidez do solo e para se conhecer o nível de disponibilidade de nutrientes. Já a análise foliar, por sua vez, é instrumento de grande utilidade para avaliar o estado nutricional das plantas. Ela permite que, de posse de tabela-padrão de interpretação, possam detectar-se possíveis desequilíbrios de nutrientes de correção durante o ciclo. Na cultura da macieira, grande parte dos produtores utiliza a análise foliar como informação para a tomada de decisão da adubação do pomar.

Também é comum a ocorrência de distúrbios fisiológicos nos frutos, na pré e pós-colheita. $\mathrm{Na}$ maioria dos casos, a incidência destes distúrbios ocorre em frutos armazenados. Inúmeros trabalhos mostram que a análise dos teores minerais na polpa, na colheita ou três semanas antes da colheita, constitui-se método seguro para prognosticar a ocorrência destes distúrbios fisiológicos, desde que se tenham padrões confiáveis, determinados para diferentes métodos de amostragem e determinações dos teores de nutrientes na análise de frutos de macieira para as condições locais. A análise dos teores minerais na polpa dos frutos é utilizada em nível de produtores, visando a melhor conservação dos frutos. A Epagri/ Estação Experimental de Caçador desenvolveu estes padrões e há mais de 25 anos vem prestando este importante serviço de análise para os produtores. 


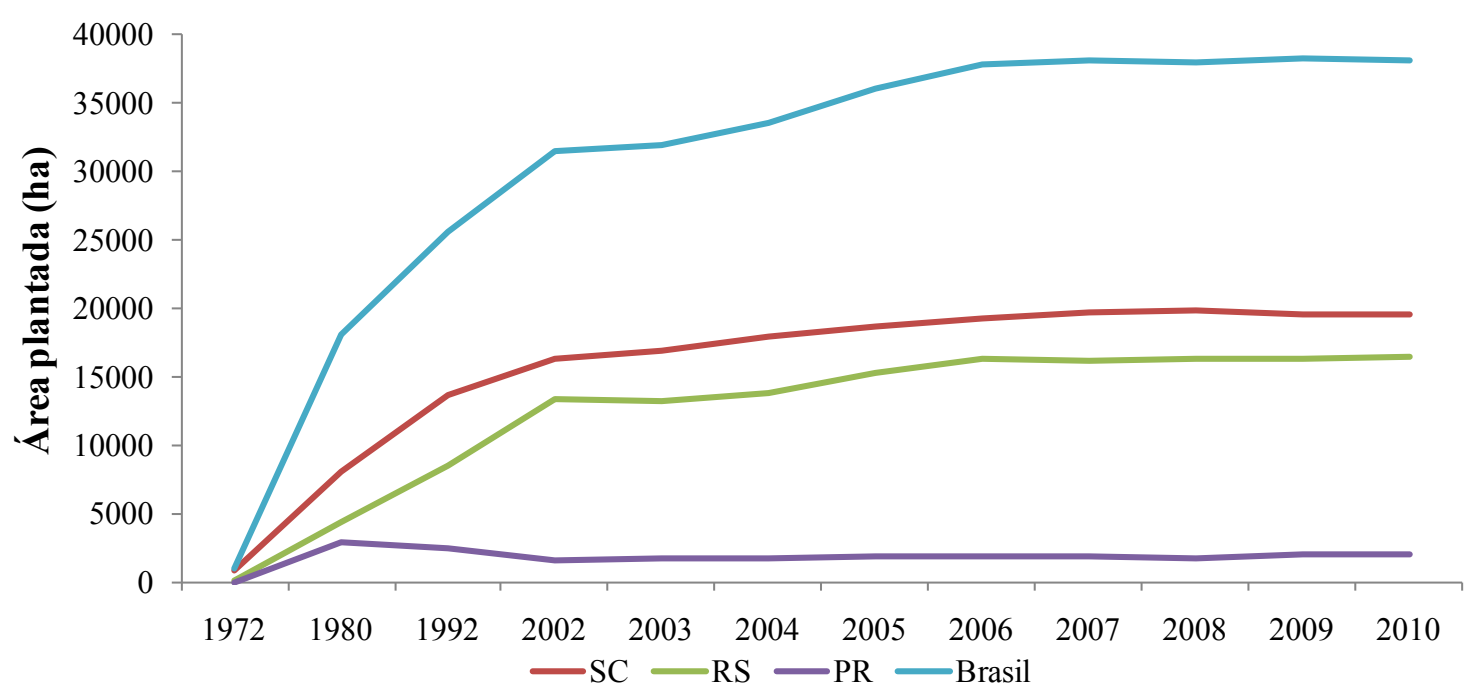

FIGURA 1 - Evolução da área plantada de macieira (ha) nos principais estados produtores e no Brasil. Caçador-SC, 2011.

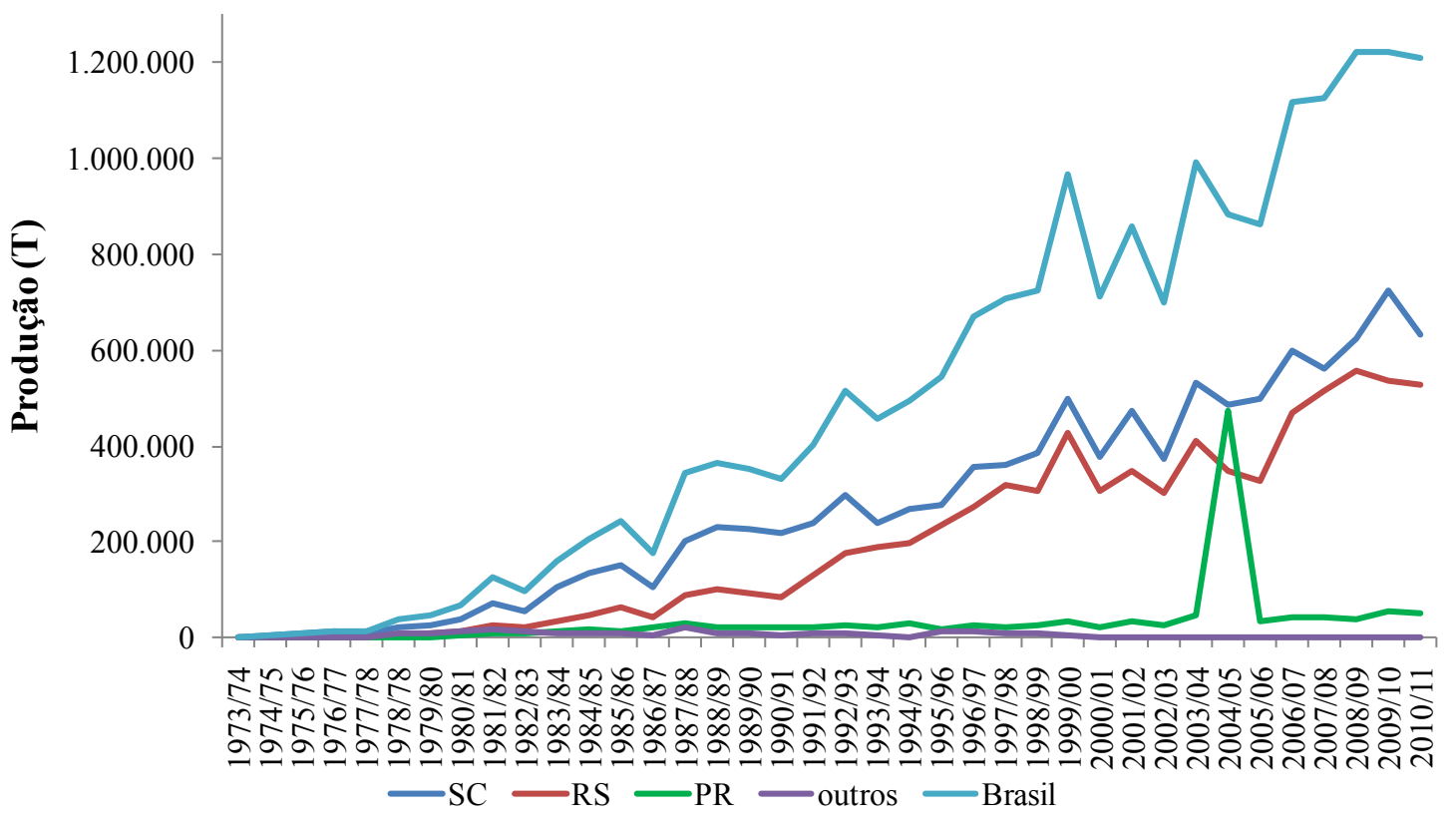

FIGURA 2 - Evolução da produção de maçã $(\mathrm{T})$ nos principais estados produtores e total no Brasil. Caçador-SC, 2011. 


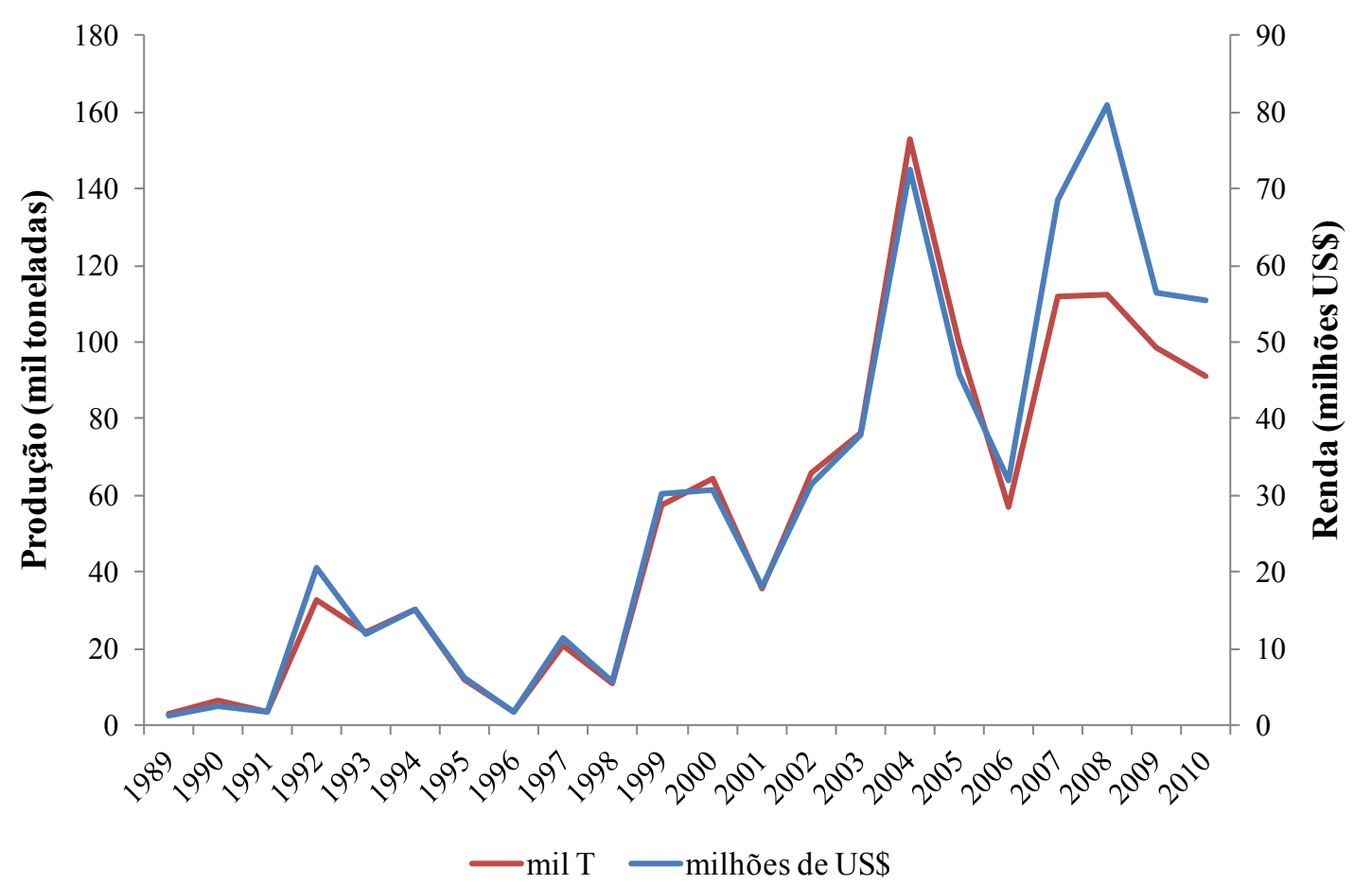

FIGURA 3 - Evolução das exportações brasileiras de maçã (toneladas e valor US\$). Caçador-SC, 2011.

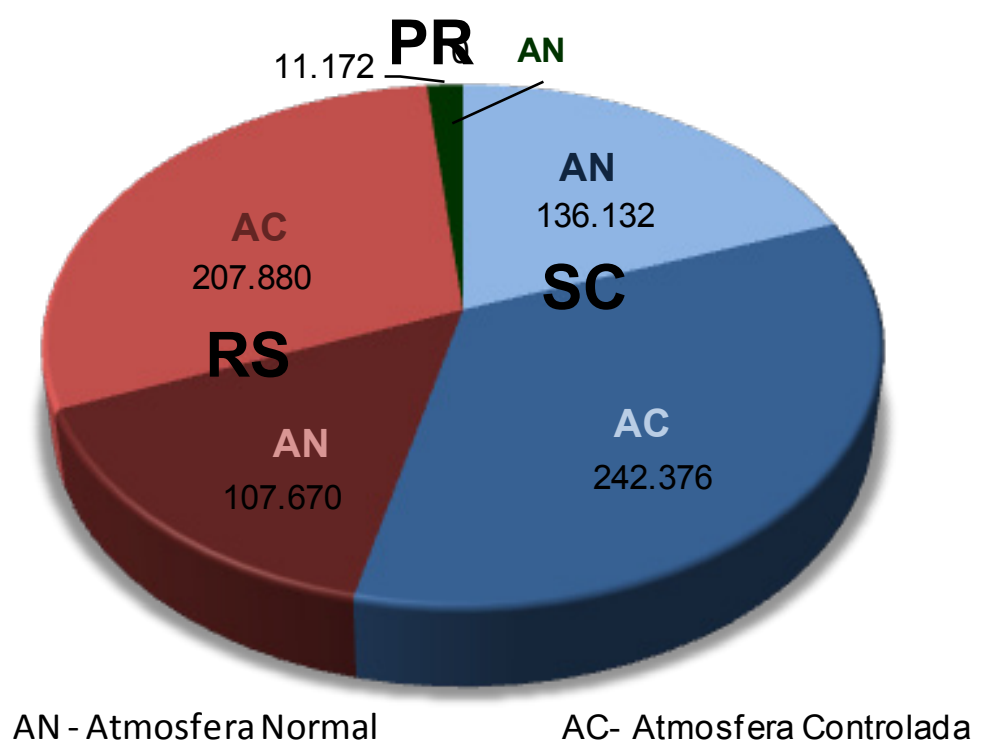

FIGURA 4 - Capacidade estática de estocagem de maçã nos principais estados produtores. Caçador-SC, 2011. 
TABELA 1 - Influência da densidade de plantio sobre a produtividade (T/ha) da cultivar Royal Gala/M9 em São Joaquim-SC, 2011.

\begin{tabular}{lccccccccc}
\hline Espaçamento & $\mathbf{2}^{\circ}$ ano & $\mathbf{3}^{\circ}$ ano & $\mathbf{4}^{\circ}$ ano & $\mathbf{5}^{\circ}$ ano & $\mathbf{6}^{\circ}$ ano & $\mathbf{7}^{\circ}$ ano & $\mathbf{8}^{\circ}$ ano & $\mathbf{9}^{\circ}$ ano & $\mathbf{1 0}^{\circ}$ ano \\
\hline $\mathbf{4 , 0 \times 0 , 5}$ & 23,8 & 45,4 & 57,0 & 48,4 & 61,6 & 56,3 & 43,8 & 61,4 & 81,2 \\
$\mathbf{4 , 0 x 1 , 0}$ & 23,9 & 29,5 & 42,9 & 42,5 & 53,4 & 41,8 & 38,7 & 41,5 & 68,0 \\
$\mathbf{4 , 0 x 1 , 5}$ & 12,7 & 22,9 & 34,5 & 31,4 & 40,8 & 37,8 & 28,9 & 37,9 & 49,6 \\
\hline
\end{tabular}

TABELA 2 - Influencia da densidade de plantio sobre a produtividade (T/ha) da cultivar Fuji/M9 em São Joaquim-SC.2011.

\begin{tabular}{lrrrrrrrrc}
\hline Espaçamento & $\mathbf{2}^{\circ}$ ano & $\mathbf{3}^{\circ}$ ano & $\mathbf{4}^{\circ}$ ano & $\mathbf{5}^{\circ}$ ano & $\mathbf{6}^{\circ}$ ano & $\mathbf{7}^{\circ}$ ano & $\mathbf{8}^{\circ}$ ano & $\mathbf{9}^{\circ}$ ano & $\mathbf{1 0}^{\circ}$ ano \\
\hline $\mathbf{4 , 0 x 0 , 5}$ & 33,3 & 62,2 & 51,4 & 62,3 & 84,2 & 71,7 & 68,1 & 89,3 & 111,0 \\
$\mathbf{4 , 0 x 1 , 0}$ & 21,3 & 50,2 & 44,1 & 49,9 & 71,6 & 65,6 & 62,2 & 68,5 & 93,5 \\
$\mathbf{4 , 0 x 1 , 5}$ & 12,4 & 41,4 & 26,5 & 41,2 & 52,8 & 52,4 & 59,4 & 58,9 & 70,6 \\
\hline & & & & & & & & Fonte: Pereira, A.J., 2007
\end{tabular}

\section{CONSIDERAÇÕES GERAIS}

A sustentabilidade da cultura da macieira ao longo dos anos foi conseguida com a introdução de importantes tecnologias que permitiram avanços na produtividade e na qualidade da fruta. Estas tecnologias sustentam o crescimento da cultura da macieira, de maneira que, em 40 anos, o Brasil foi capaz de tornar-se autossuficiente, abastecendo o mercado de norte a sul do País e abrindo mercado de exportação em diversos países.

\section{REFERÊNCIAS}

ABPM. Associação Nacional dos Produtores de Maçã. Disponível em: <http://www.abpm.org.br/>. Acesso em: 25 maio 2011.

ANUÁRIO BRASILEIRO DA FRUTICULTURA. Rede protetora. Santa Cruz do Sul: Gazeta, 2008. p. 44-45.

BLEICHER, J. Historia da macieira. In: EPAGRI. A cultura da macieira. Florianópolis, 2002. 743p. CEPA/EPAGRI. Síntese anual da agricultura de Santa Catarina 2009-2010. Florianópolis, 2010. p.315.

FIORAVANÇO, J. C. MAÇÃ BRASILEIRA: Da importação à auto-suficiência e exportação - A tecnologia como fator determinante. Informações Econômicas, São Paulo, v.39, n.3, p.56-67, 2009.
KREUZ, C. L.; BERNARDI, J. História e importância da macieira. In: EPAGRI. Manual da cultura da macieira. Florianópolis, 1986. 562p.

MELLO, L. M. R. de. Produção e mercado brasileiro de maçã. Bento Gonçalves: Embrapa Uva e Vinho, 2004. (Comunicado Técnico, 50)

OJIMA, M.; CAMPO-DALL'ORTO, F.A.; BARBOSA, W.; RIGITANO, O. Fruticultura de clima temperado. In: FURLANI, A.M.C.; VIÉGAS, G.P. O melhoramento de plantas no Instituto Agronômico. Campinas: Instituto Agronômico, 1993. p.157-194.

PEREIRA, A. J. Efeito dos porta-enxertos M.9 e M.26, na densidade de plantio da macieira, cvs. Royal Gala e Fuji. In: ENCONTRO NACIONAL SOBRE FRUTICULTURA DE CLIMA TEMPERADO, 10. 2007, Caçador, SC. Anais... Caçador: Epagri, 2007. p. 195-201.

SANTOS, L. W. Primórdios da pesquisa com Maçã em santa Catarina, Agropecuária Catarinense, Florianópolis, v.7, n.3, p.20-22, 1994.

SCHMIDT, W. O setor macieiro em Santa Catarina - formação e consolidação de um complexo industrial. 1990. 250f. Dissertação (Mestrado em desenvolvimento agrícola)- Instituto de Ciências Humanas e Sociais, Universidade Federal do Rio de Janeiro, Itaguaí, 1990. 